\title{
A note to our subscribers
}

Volume 73, Number 2 (1983) page 151

M.G. Hadfield and R.E. Young: Planctosphaera (Hemichordata: Enteropneusta) in the Pacific Ocean

Due to a printer's error the second paragraph of the second column is incorrect. We would therefore like to ask all subscribers to cut out this corrected version and adhere it over the original text in the journal. May we please ask you to excuse this unfortunate error.

Springer-Verlag

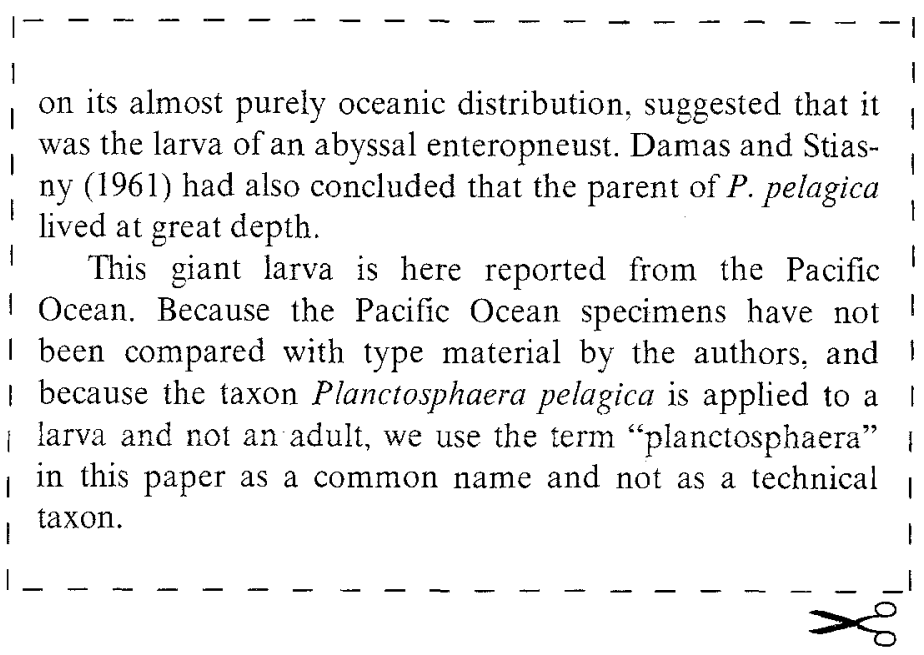

